\title{
Ensuring Environmental Safety Based on the Modeling of Biological Process of Oily Sewage
}

\author{
Azimov Yu. I. \\ Kazan Federal University, Institute of Management, Economics and Finance, Kazan, 420008, Russia
}

Savdur S.N.

Kazan Federal University, Institute of Management, Economics and Finance, Kazan, 420008, Russia

Email :savdur.svetlana@yandex.ru.

Fesina E.L.

Kazan Federal University, Institute of Management, Economics and Finance, Kazan, 420008, Russia

\section{Doi:10.5901/mjss.2014.v5n24p372}

\section{Abstract}

The article discloses the main areas of institutional support for sustainable ecological and economic development of economic entities on the basis of conceptual approaches to the systematization of methods and mechanisms for the protection of their economic interests. There described the mathematical basis of Petri nets used in the modeling and design of the module bioremediation of hydrocarbon wastewater. There described the technique of two-tier system of the modeling process of biochemical treatment of oily wastewater, as well as a model developed by the authors in the form of a modified Petri nets and software package management system of biochemical treatment of wastewater.

Keywords: ecological and economic safety, modified Petri nets, wastewater bioremediation, biochemist technology system, hierarchical structural model, system modeling.

\section{Introduction}

The effectiveness of the environmental mechanism largely depends on the structure of environmental costs. In Russia, the direct costs to combat pollution of more than $50 \%$ are costs associated with the biological treatment of sewage. Modern production lines and biotechnology industries are characterized by a complex multi-level structure, they can therefore be regarded as a complex cybernetic systems. Due to the complexity of the modeling and analysis of such systems, there is a need to attract modern methods of mathematical and computer modeling.

\section{Materials and Methods}

Researchimg the problems in the study, there are used the methods of systems analysis, computer simulation of Petri nets theory, graph theory, numerical methods for solving equations.

\section{Results of the Study}

According to the degree of concentration of industrial production of the Republic of Tatarstan is heterogeneous. Therefore, the level of environmental risk is not evenly distributed across its territory. The greatest danger of ecological impacts on the environment are discharges of water containing dirt of petrochemical industries. Purification of effluents is a prerequisite for the ecological balance of the environment. However, the existing wastewater treatment technology is not good enough and does not provide its efficient level. Modern wastewater treatment plants of large petrochemical enterprises are structurally complex systems. Therefore, their lance operation conditions in which the wastewater has dynamically varying parameters such as the composition and flow rate until the indicators salvo reset are the substantial interest [1]. The effective functioning of these systems can be achieved with the help of modern methods of information processing, using the methods of system analysis of complex objects based on a mathematical description of the process 
[2].

In accordance with the principles of system analysis of industrial plant Biological wastewater treatment BWT is a biochemical technological system (BChTS) comprising a set of units interrelated with material, thermal and information flow, each of them has a hierarchical structure [3]. BWT can be divided into interconnected subsystems characterized by a hierarchical structure. Management tasks at each level of the hierarchy of production are different, but the general objective is wastewater treatment to standard indicators or to provide working-level water supply [4].

One of the major way in the study of complex systems which serve BWT is a information approach based on the mathematical modeling of the object [5]. Modeling and computer experiments with model - replacement facility are an effective means to create a management system, consider the behavior of the object in emergency situations, to evaluate its structure and control laws, as well as to take into account the stochastic nature of disturbances $[6,7]$. There are two approaches to the modeling of real objects. In the first approach the object is represented as a dynamic system with continuous variable. The functional mathematical model of the object is a system of ordinary differential equations, partial differential equations and algebraic polynomials obtained by the regression analysis to characterize the input (output) of the system. This approach is widely used in modeling chemical processes with a continuous organization of the process $[8,9]$ provided that it is stationary and the immutability of physical and chemical parameters. In the second approach, the object is represented as a dynamic system with discrete events (DSDE). These include manufacturing systems, assembly lines, computer networks.

This DSDE class also includes discrete-continuous biochemist technological systems. Solving problems of management organization of such discrete dynamical systems requires the use of special mathematical methods. Traditionally, for this purpose there are used methods of finite automata, logical-linguistic and simulation models, as well as of the theory of graphs and networks, Petri nets (PN) [10]. Based on a comparative analysis, as the main mathematical modeling of the theory is selected the PN. The PN allow to simulate discrete concurrent asynchronous processes [10], to obtain a graphical representation of the network, describe the system at different levels of abstraction, present the system hierarchy [11], analyze models using modern application package.

\section{Application of the Results}

Using the system analysis methods allows the development of a control system of wastewater treatment installation of petrochemical plants, which includes the construction of a mathematical model of the lower and upper levels of functioning. On the lower level of functioning there is determined an analytical model of the bioreactor. This allows you to provide wastewater treatment to the maximum allowable concentration. On the upper level of functioning, network models are built in a joint venture that provides flow control to install.

Block diagram of Biological wastewater treatment (BWT) installation is shown in Figure 1.

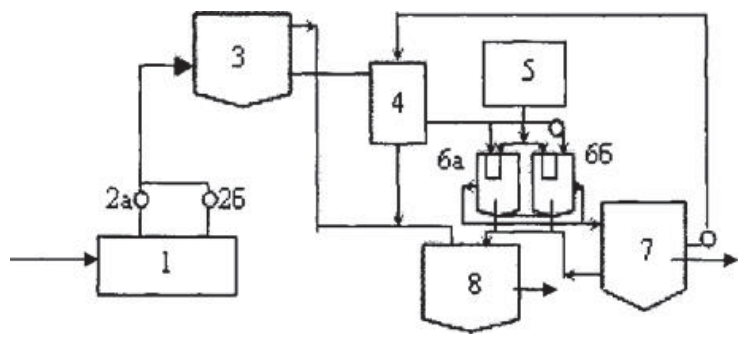

Fig. 1. Block diagram of Biological wastewater treatment (BWT) installation

Block diagram of the apparatus includes: 1 - drive effluents; $2 a$ and $2 b$ - pumps, 3 - primary clarifier; 4 - averager; 5 capacity for micro-organisms and bio-stimulants; $6 a$ and $6 \mathrm{~b}$ - jet settlers; 7 - secondary settling tank; 8 - slurry tank .

Upper level of bioremediation process of OW in industrial plants can be efficiently described by PN [12]. To describe this system, we propose the use of N-schemes based on mathematical apparatus PN, one of its advantages is the possibility of representing the network model in analytical form to automate the process of analysis, and graphical form for clarity of models [10].

In the analysis of chemical-engineering or a biochemical process flow diagrams there should be considered the main limitation of the formalism of $\mathrm{N}$-schemes which consists in the fact that they do not consider the temporal characteristics of the simulated systems, since the response time of transition is considered to be zero. Given these 
conditions, we propose to use MPN - PN of the form $\mathrm{C}=<\mathrm{P}, \mathrm{T}, \mathrm{I}, \mathrm{O}, \mathrm{M}, \tau_{1}, \tau_{2}>[13]$,

where $T=\{t\}\}$ - finite nonempty set of symbols (transitions) estimated from the number of servings of conventional products with a continuous feeding in the apparatus of the flowsheet;

$\mathrm{P}=\left\{\mathrm{p}_{\mathrm{i}}\right\}$ - finite nonempty set of symbols (position) which are understood many devices flowsheet;

I: PXT $\rightarrow\{0,1\}$ - input function which gives the set of its position $\mathrm{p}_{\mathrm{i}} \in \mathrm{I}(\mathrm{t})$; ; for each transition $\mathrm{ti}_{\mathrm{i}}$;

$\mathrm{O}:$ PxT $\rightarrow\{0,1\}$ - output function which displays a transition to a set of output positions $\mathrm{p}_{\mathrm{i}} \in \mathrm{O}\left(\mathrm{t}_{\mathrm{j}}\right)$;

$\mathrm{M}: \mathrm{P} \rightarrow\{1,2,3 \ldots\}$ - function labeling (marking) network which assigns to each position a non-negative integer equal to the number of labels in this position, changing in the process of the network.

Actuation of the transition instantaneously changes the markup $M(p)=\left(M\left(p_{1}\right), M\left(p_{2}\right), M\left(p_{3}\right) \ldots M\left(p_{n}\right)\right)$ for marking $\mathrm{M}^{\prime}(\mathrm{p})$ by the following rule:

$M^{\prime}(p)=M(p)-I\left(t_{j}\right)+O\left(t_{j}\right)$

Equation 1 indicates that a transition tj removes one of each tag of its input position and adds one tag to each of the output positions.

$\tau_{1}: \mathrm{T} \rightarrow \mathrm{N}$ и $\tau_{2}: \mathrm{P} \rightarrow \mathrm{N}$ functions that define the time-delay at the transition and time delay in the position.

The dynamics performing MPN is defined by the marks movement simulating the balance of discrete flows of intermediates in a defined limits on the volume of device BWT setting.

For chemical-technological industries in analytical and graphical form the status of individual devices (positions) process can be represented in Table 1.

Table 1. The status of individual devices (positions) in the technological process of analytical and graphical forms

\begin{tabular}{|c|c|}
\hline Technological scheme of the device & Model of the device in the form of a Petri net \\
\hline 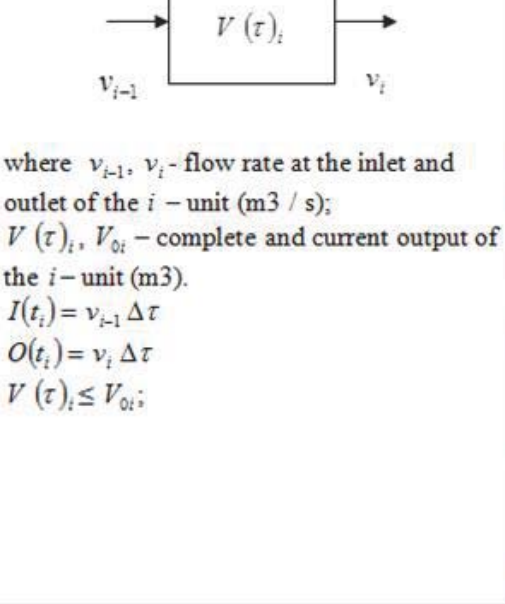 & $\begin{array}{l}\mathrm{p} 1-\text { position informing the current volume of the } \\
\text { portion of the precursor in the machine; } \\
\mathrm{M}(\mathrm{p} 1)=V_{0:} \text {; } \\
\mathrm{p} 2-\text { position informing the current volume of the } \\
\text { treated portion of the machine; } \\
\mathrm{p} 3-\text { position informing the availability of free } \\
\text { space in the device; } \\
\mathrm{M}(\mathrm{p} 2)=V_{0:}-V(\tau)_{i} \text {; } \\
\mathrm{t} 1-\text { transition simulating the load of intermediate } \\
\text { portions in the device; } \\
\mathrm{t} 2-\text { transition simulating the processing the loaded } \\
\text { portions; } \\
\mathrm{t} 3-\text { transition simulating the discharging the treat- } \\
\text { ed portions. }\end{array}$ \\
\hline
\end{tabular}

The considered PN modification allows to analyze the functioning of the system units under emergency situations, switching the control at the network layer, as well as technological schemes discrete-continuous processes for sustainable, stable system state.

Efficiency of wastewater treatment at the facility is defined by the management of the technological process directly on the lower level by making the kinetic modes of the bioreactor. Depending on the indicators of pollution of wastewater there are supplied metered nutrients, biocatalyst, there balanced the acid number, bioremediation temperature.

Mathematical model of biokinetics is described in an analytical form as a system of equations:

$V \frac{d B^{(1)}}{d t}=\left(B^{(0)}-B^{(1)}\right) * v+q_{B} V ;$
$V \frac{d S^{(1)}}{d t}=\left(S^{(0)}-S^{(1)}\right) * v-q_{S} V$,
Initial conditions:
$B^{(0)}=$ const, $S^{(0)}=$ const,

where $B^{(0)}, B^{(1)}$ - concentration of microorganisms, respectively, in the input stream and the mixing zone; $S^{(0)}, S^{(1)}$ concentration of hydrocarbons of oil, respectively, in the input stream and in the mixing zone; $q_{B}$ - growth rate of the 
microorganisms; qs - rate of oil oxidation by microorganisms; $V$ - volume of a zone of the apparatus; $v$ - flow rate.

Kinetic characteristics of the process $q_{B}$ and $q_{s}$ are determined by empirical relations 5 and 6 :

$$
\begin{aligned}
& q_{B}=\frac{m_{\text {max }} S B}{\left.\left(1+H^{+} / K_{1}+K_{2} / H^{+}\right)\left(K_{S}+S\right) \exp \left[t_{\text {opt }}^{0}-t^{0}\right)^{2} / d\right]\left(1+C_{\text {kam }} / K_{\text {kam } 1}+K_{\text {kam } 2} / C_{\text {kam }}\right)}-K_{d} B \\
& q_{S}=-\frac{1}{Y_{S}} \frac{m_{\max } S B}{\left.\left(1+H^{+} / K_{1}+K_{2} / H^{+}\right)\left(K_{S}+S\right) \exp \left[t_{\text {opt }}^{0}-t^{0}\right)^{2} / d\right]\left(1+C_{\text {axam }} / K_{\text {axml }}+K_{\text {kam } 2} / C_{\text {axam }}\right)} \text {, }
\end{aligned}
$$

where $\mathrm{m}_{\max }$ - is maximum specific growth rate of microorganisms; $K_{d}$ - is rate constant of microorganisms dying; $Y_{s}$ - is coefficient for substrate binding amount of biomass and amount of the past on its growth substrate (hydrocarbons); $\mathrm{K}_{\mathrm{s}}$ - is half-saturation constant (affinity constant to the substrate); $K_{1}$ and $K_{2}$ - are inhibition constants by hydrogen ions $\left(K_{1}\right.$ describes inhibition in acidic region $\left.\left(\mathrm{H}^{+}>>K_{1}\right)\right) ; K_{2}$ - describes the inhibition in the alkaline region $\left(\mathrm{K}_{2}>>\mathrm{H}^{+}\right) ; \mathrm{H}^{+}$- is hydrogen ions concentration; $t^{0}{ }_{\text {opt }}$ - is temperature optimal for microbial growth; $t^{0}$ - is current temperature; $d$ - is temperature range; $\mathrm{C}_{\text {кат }}$ - is concentration ofbiocatalysts compounds; $\mathrm{K}_{\text {кат1 }}$ and $\mathrm{K}_{\text {кат2 }}$ - are effective inhibition constants activation in their respective fields, $\mathrm{pK}_{1}$ and $\mathrm{pK}_{2}$ - are dissociation constants.

Identification of kinetic parameters of the reaction rate $q_{в}$ and $q_{s}$ was based on data obtained in the plant laboratory.

The system of equations 2 and 3 is solved together with the equations of the kinetics of biochemical transformation 5,6 by Runge-Kutta method [13].

Model calculations are performed on an example of Jet settlers. The permissible degree of OW bioremediation is achieved by controlling the flow rate of wastewater fed to the bioreactor inlet.

Thus, we developed a mathematical model of the process of OW bioremediation in JS, which is the basic model to describe this process, defines the operation of the plant of OW cleaning with an neutralization efficiency of petroleum products to the maximum allowable concentration for 1.2 hours of cleaning and it allows to intensify this process for temporary parameter.

To manage the process of OW bioremediation on the upper level, a mathematical model of the technological scheme and its software implementation is developed. The mathematical model of OW bioremediation is developed as MPN which implementation helped to explore the communication system and the laws of functioning of the unit as a whole. Also there are constructed the models of the main devices implementing OW bioremediation process [12]. Of the PN models of typical devices was synthesized a model of the entire system (Fig. 2).

Using the PN model we have developed a software package of the technological feasability of OW bioremediation module simulating the operation of bioremediation in virtual time. With SCADA- technology means TRACE MODE was designed software package of process control system of biological OW treatment [14]. The system of technological process control allows to perform supervisory control of the main elements of the management system, stop the system BWT and analyze its state as a whole, and in order to anticipate emergency situations [5].

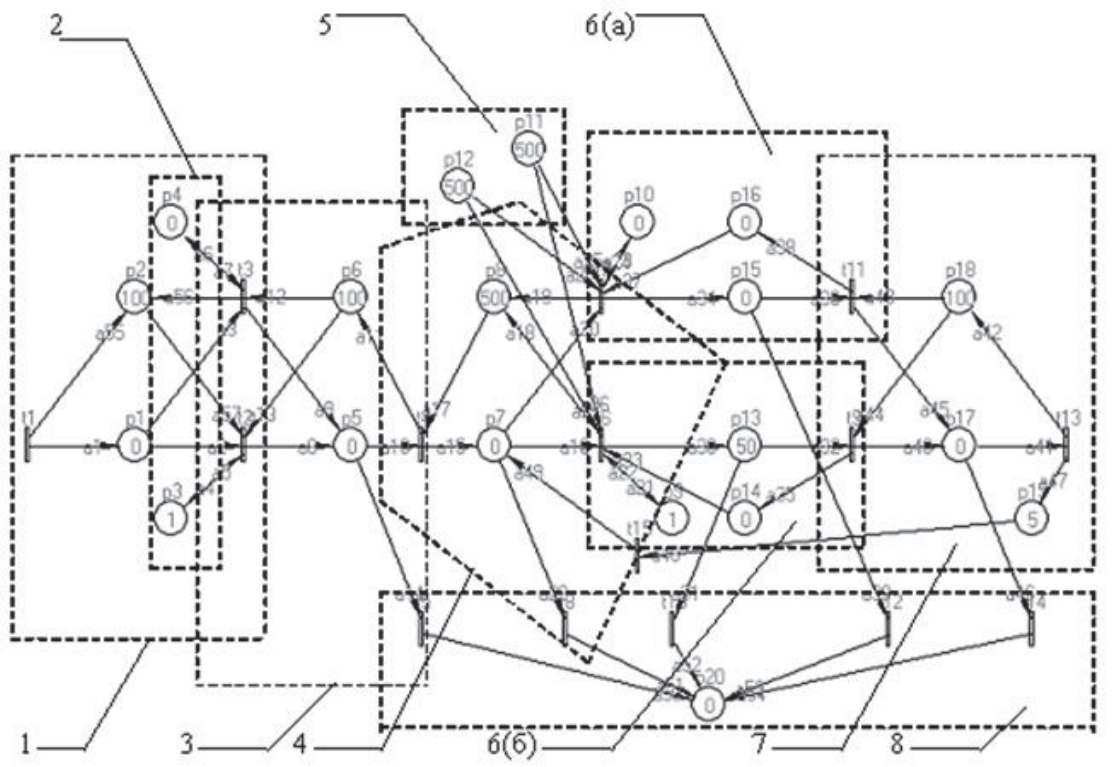

Fig. 2. Model of the process module as MPN 


\section{Conclusion}

Ensuring environmental safety of petrochemical plants, characterized by significant amounts of pollutant discharge, involves the solution of problems of the organization of the technological wastewater treatment plants to the level of standard indicators or water recycling. The implementation of this task is defined with the information analysis of technological process through the development of a mathematical model in the form of OW bioremediation.

The technique of two-level system of technological process modeling BWT proposed in the work, allows the analysis of such industrial units operation in a dynamically changing process parameters and in a timely manner to prevent the occurrence of environmental risks.

\section{References}

Fesina, E., Savdur, S. Modeling of Sewage Bioremediation as a Modified Petri Net (2014) World Applied Sciences Journal 31 (6), pp. 1191-1197.

Hunt, J. C. R., Timoshkina,Y., Baudains, P. J, Bishop, S. R. System Dynamics Applied to Operations and Policy Decisions // European Review 20(3), 2012. pp. 324-342.

Motameni, H., Movaghar, A., Shirazi, B., Aminzadeh, M., Samadi, H. Analysis Software with an Object-Oriented Petri Net Model (2008) World Applied Sciences Journal 3 (4), pp. 565-576.

Kadochnikova E. Methodological Issues of Macroeconomic Accounting (Review) (2013) World Applied Sciences Journal 24 (6), pp. 719 $723,$.

Huilinir, C., Aspe, E., Roeckel, M. Modeling of the denitrification/anaerobic digestion process of salmon fishery wastewater in a biofilm tubular reactor // Journal of Environmental Management 92, 2011. pp. 1591-1608.

Haroonabadi, A., Teshnehlab, M., Movaghar, A. A Novel Method for Behavior Modeling in Uncertain Information Systems (2008) World Applied Sciences Journal 3 (5), pp.797-805.

Ruiz, M., Sin, G., Berjaga, X., Colprim, J., Puig, S., Colomer, J. Multivariate Principal Component Analysis and Case-Based Reasoning for monitoring, fault detection and diagnosis in a WWTP // Water Science, Technology 64 (8), 2011. pp. 1661-1667.

Peter, P., Determination of Biological Degradability of Organic Substrates // Water Research 10, 1976. pp. 231-235.

Buswell, A.M., Mueller, M.F. Mechanisms of Methane Fermentation // Industrial and Engineering Chemistry 44, 1952. pp. 550-552.

Guest Editors, MengChu Zhou, Li ZhiWu. Special issue on «Petri nets for system control and automation» (2010) Asian Journal of Control 12 (3), pp.237-239.

Barzegar, B., Motameni, H. Modeling and Simulation Firewall Using Colored Petri Net (2011) World Applied Sciences Journal 15 (6), pp.826-830.

Albert W., Yao, L., Zhiming Ji, Liao H. T. A Petri nets-based process planning system for wastewater treatment (2010) Asian Journal of Control 12 (3), pp. $281-291$.

Caffo, M., Czyz, H., Remiddi, E. Numerical evaluation of the general massive 2-loop sunrise self-mass master integrals from differential equations // Nuclear Physics B 634, 2002.pp. 309-325.

Nasby, G., Phillips, M. SCADA standardization: Modernization of a municipal waterworks with SCADA standardization: Past, present, and planning for the future // InTech58 (5-6), 2011. P. 1. 